\title{
The Effect of the Streamlined Shoe on Dynamic Gait Change and Foot Plantar Pressure in Healthy Young Adults
}

\author{
Jae-Hun Shim ${ }^{1}$, Hwa-Soo Koong ${ }^{2}$, Seung-Chul Chon ${ }^{3}$ \\ ${ }^{1}$ Department of Physical Therapy, The University of Baekseok, Cheonan, 330-704 \\ ${ }^{2}$ Department of Dental Hygiene, The University of Konyang, Daejeon, 302-718 \\ ${ }^{3}$ Department of Physical Therapy, The University of Konyang, Daejeon, 302-718
}

\begin{abstract}
Objective: This study compared the effects of streamlined shoes on dynamic gait and foot plantar pressure in healthy young adults. Background: With the importance of ankle and lower extremity mechanism, streamlined shoes are contributing to a static gait factors. However, the study of dynamic gait factor is still insufficient. Method: Sixty subjects were randomly allocated to two groups: experimental group $(\mathrm{n}=30)$ and control $(\mathrm{n}=30)$, respectively. The experimental group performed streamlined shoes, whereas the control group applied usual shoes. Main outcome measurements were assessed contact time, step length and foot plantar pressure using gait analysis with the treadmill. Independent t-test was used to compare the both groups. Results: Compared with control group, contact time of forefoot, midfoot and hindfoot decreased significantly in experimental group $(p<.05)$, Step length increased significantly in experimental group $(p<.05)$. Foot plantar pressure of midfoot and hindfoot increased significantly in experimental group $(p<.05)$, whereas that of forefoot did not show significantly in experimental group $(p>.05)$. Conclusion: Our findings suggest that streamlined shoes was more effective than usual shoes in dynamic gait change including contact time and step length and foot plantar pressure in healthy young adults. Application: The results of streamlined shoes might help to control for the gait of industrial workers.
\end{abstract}

Keywords: Ankle, Foot plantar pressure, Gait analysis, Streamlined shoes

\section{Introduction}

보행은 일상생활 중 가장 많이 수행되는 동작으로 신체의 가속과 제어를 위해 반복적인 하지 관절의 굴곡과 신전 동작 을 수반한다(Perry, 1992). 직립보행은 다른 척추동물과 달 리 보행 시 체중의 3 배까지 높은 충격을 근육, 건, 인대 및 관절에 전달하게 된다. 이러한 과부하는 요통, 피로골절, 연 골 연하증 및 파괴 등과 같은 상해의 원인이 되며 예방학적
관점에서 중요한 지표이다(Waters \& Mulroy, 1999).

이러한 상해의 원인들을 예방하고, 외부의 열, 냉 및 물리적 외력으로 인한 손상으로부터 신체 및 하지 (lower extremity)를 보호하는 역할을 신발이 하게 된다. 신발은 보행 시 지면으로부터의 충격을 흡수하여 발과 하지의 피 로를 줄여줌으로써 상해의 예방 및 안정성을 증가시킨다 (Najafi et al., 2013). 기능적 측면에서 신발 굽의 높이 및 형태에 따라 초기 입각기 시에 전달되는 부하 및 충격의 양은 달라지며 이차적으로 요추 및 골반의 각도에도 역학

Corresponding Author: Seung-Chul Chon. Department of Physical therapy, The University of Konyang, Daejeon, $302-718$.

Phone: +82-42-600-6327, E-mail: keyjune@konyang.ac.kr

Copyright@2013 by Ergonomics Society of Korea(pISSN:1229-1684 eISSN:2093-8462). All right reserved.

(c) This is an open-access article distributed under the terms of the Creative Commons Attribution Non-Commercial License(http://creativecommons.org/licenses/by-nc/3.0/), which permits unrestricted non-commercial use, distribution, and reproduction in any medium, provided the original work is properly cited. http://www.esk.or.kr 
적 변화를 미치게 된다(Mika et al., 2012). 예를 들어, 굽 이 높은 형태의 신발은 보행 시 발목의 입각기에 족저굴곡 (plantar flexion), 뒤침(supination) 및 전족부(forefoot) 의 압력을 증가시키는 것으로 보고되어 있다(Waters \& Mulroy, 1999).

최근 몇 년간 신발 굽에 대한 문제점 개선을 위하여 밑창 의 형태를 유선형으로 설계하여 재활의학, 정형의학, 스포츠 산업 및 건강관련 분야에 보급화되고 있다. 이러한 유선형 신발의 구조는 발의 일정한 폭과 길이 유지를 위하여 중족 부에 단단한 재질의 바(bar)를 위치시키고 보행의 안정성을 위하여 후족부가 전족부보다 두꺼운 재질과 넓은 모양으로 둥근 바닥창(rocker sole)을 이루고 있다. 이러한 구조는 발 뒤꿈치 닿기 (initial contact)부터 발가락 떨어지기 (preswing)까지 신발을 구부러뜨리지 않고 발을 구르게 하여 발바닥의 압력을 감소시킴으로써 통증, 변형 및 경직과 관련 된 발과 발목의 동작을 회복시켜주게 된다(Moraes et al., 2012; Romkes et al., 2006).

유선형 신발의 효과 입증을 위한 관련연구들을 보면, Najafi 등(2013)은 이중 둥근 바닥창(double rocker), 음 성 뒷굽 바닥창(negative heel rocker), 발가락 쪽 둥근창 (toe-only rocker) 과 같은 유선형 신발의 족저압을 측정한 결과 발바닥의 압력이 모두 분산되고 전족부의 압력이 유의 하게 감소되어 당뇨병 환자와 같은 발의 궤양성 질환자에게 효과적이라고 발표하였고, Stewart 등(2007)은 발바닥의 부위별 족저압 검사가 압력측정을 통한 신체의 균형 및 보행 능력을 가장 정확하게 평가할 수 있는 용이한 방법이라고 하 였다.

지면과의 접촉시간은 체중 하중이 시작되는 발 뒤꿈치 닿 기부터 접촉면접이 최대가 되고 뒤꿈치가 지면으로부터 떨 어지는 순간인 중간지지(midstance) 구간을 거쳐 발가락이 지면으로부터 떨어지는 마지막 구간까지 보행의 안정성과 높은 관련성이 있다. Paton 등(2013)은 안정성이 떨어지는 근력이 저하된 노인에게서 지면과의 접촉시간이 길게 나타 난다고 하였고, Najafi 등(2013)은 다양한 종류의 유선형 신발들은 입각기(stance phase) 전 구간에 굴림현상으로 인 하여 접촉시간 단축 및 보행의 안정성에 대하여 발표하였다.

앞발 뒤꿈치에서 뒷발 뒤꿈치까지의 거리를 보폭길이 (step length)라고 하며, 이는 보행 시 개인마다 최저 에너 지 소모를 통하여 적합한 보폭길이를 갖는다고 하였다. 보폭 길이의 변화는 에너지 소비 및 효율성 측면에서 중요한 지표 로 보행능력을 평가하며(Perry, 1992), Mika 등(2012)은 보폭길이의 증가는 에너지 소비량 증가로써 능동적인 보행 능력을 의미한다고 하였고, Taniguchi 등(2012)은 보폭길 이의 변화는 근육의 기계적 특성인 하지 근육의 장력, 힘 및 속도와 양의 상관성을 보인다고 하였다.
족저압과 관련하여, Fuller 등(2001)은 발의 뒤꿈치와 발 가락 양쪽의 기울어짐이 유선형인 신발은 발가락이 땅에서 멀어질 때 미는 힘을 도와주고 발 뒤꿈치 닿기 시에 발 뒤꿈 치 뼈에 가해지는 충격을 흡수하여 보행기능에 긍정적이라 고 보고하였고, Cambron 등(2011)은 발 뒤꿈치 닿기 시에 충격이 적절하게 발에 흡수되지 않으면 관절의 퇴행성 변화 및 요통을 초래하게 된다고 하였고, Moraes 등(2012)은 보 행 시에 지면반발력을 줄이기 위해서 특수한 신발 형태의 필 요성에 대해서 보고하였다. 즉, 보행 시 발에 전달되는 지면 반발력은 체중의 3 배 힘이 가해지며, 이를 예방하기 위한 필 요성이 지속적으로 보고되고 있다.

그러나 지금까지 발표된 선행연구들에 참고하였을 때, 유 선형 신발의 효과를 측정한 내용들은 대부분이 정적인 상태 에서 하지의 근력, 균형 및 보행능력을 연구하였고, 지면과 접촉되는 발의 면적을 구간으로 나누어 구체적으로 연구한 자료는 여전히 제한적이다. 또한, 유선형 신발의 효과에 대 해서 부정적인 결과도 보고되었다(Taniguchi et al., 2001). 따라서 본 연구에서는 일반 신발과 비교하여 유선형 신발을 착용하고 실제 보행 형태와 유사한 동적인 보행속도를 유지 하면서 유선형 신발의 면적구간을 구분하여 발의 접촉시간, 보폭길이 및 족저압에 미치는 영향을 알아보고자 한다.

\section{Method}

\subsection{Subjects}

본 실험에 동원된 실험대상은 천안소재 모대학에 재학 중 인 건강한 성인 60 명을 대상으로 하였고, 실험군(유선형 신 발 착용) 과 대조군(일반적인 운동화 착용) 30 명을 각각 배 정하였다. 모든 대상자들은 실험 전 실험 목적과 절차에 대 하여 충분한 설명을 듣고, 동의서를 작성한 후 참여하였다. 대상자들은 발목에 근골격계 질환이 없고, 족부 변형이 없어 정상적인 보행이 가능하고, 자세정렬에 문제점이 없으며, 통 증이 없고, 심폐기능에 문제가 없으며, 연구자가 지시하는 내용을 정확히 이해하고 따를 수 있는 자들로 선별하였다. 연구대상자의 일반적 특성은 Table 1 과 같다.

Table 1. General characteristics of subjects

\begin{tabular}{c|c|c|c}
\hline & $\begin{array}{c}\text { Experimental group } \\
\left(\mathrm{n}_{1}=30\right)\end{array}$ & $\begin{array}{c}\text { Control group } \\
\left(\mathrm{n}_{2}=30\right)\end{array}$ & $p$ \\
\hline Age$(\mathrm{yrs})$ & $23.06 \pm 1.77$ & $23.83 \pm 2.64$ & .192 \\
\hline Weight $(\mathrm{kg})$ & $61.93 \pm 9.59$ & $62.13 \pm 11.69$ & .943 \\
\hline Height $(\mathrm{cm})$ & $170.93 \pm 8.34$ & $168.36 \pm 2.64$ & .224 \\
\hline
\end{tabular}




\subsection{Equipment}

동적 보행 변화 및 족저압을 측정하기 위하여 연구대상자 들은 편안한 복장을 준비하고 실험군은 유선형 신발을 착용 하고, 대조군은 일반적인 신발을 착용한 후 보행방법에 대하 여 설명을 듣고, 각각 신발과 실험 환경에 적응할 수 있도록 미리 10분간 보행을 실시하도록 하였다.

본 연구는 단면조사연구(cross-sectional design) 방법 으로 보행분석 장비(WinFDM-T, Zebris, 독일)를 사용하 여 보행시 접촉시간, 보폭길이 및 족저압을 측정하였다.

보행분석 장비는 트레드밀(ap117, Apsun, 대한민국)위에 감지기가 부착된 힘판(force plateform)으로 구성되어 있으 며 노트북과 연결되어 발과 발판사이의 지면반발력 (ground reaction force)을 실시간으로 감지하여 동적 보행과 무게를 계산하여 보행 시 접촉시간, 보폭길이 및 족저압을 측정한다. 표본 주파수(sampling frequence)는 $50 \mathrm{~Hz}$ 이며 대상자는 트레드밀 위에 올라가 $3.0 \sim 4.0 \mathrm{~km} / \mathrm{h}$ 속도로 보행을 실시하 도록 하였다. 시선은 상방 20도를 고정하고 편안하게 팔을 흔들어 체간에서 자연스런 동작이 일어나도록 하였다. 보행 중 소리 및 시간에 의한 외부 변인이 작용하지 않도록 독립 된 공간에서 조용하게 보행을 실시하였고, 대상자에게는 어 떠한 외부 피드백이 제공되지 않도록 하였다. 측정값은 3 회 측정하여 평균값을 분석하였다.

\subsection{Procedure}

실험에 사용된 유선형 신발은 일반인들이 보편적으로 자 주 사용하는 제품을 이용하였다(Figure 1). 유선형 신발은 기본 둥근 바닥창(basic rocker sole)의 형태로 가장 많이 사용되는 유선형 신발로 발 뒤꿈치와 발가락 쪽에 기울기가 완만한 각도를 형성하여 중족골 (metatarsal bone)쪽의 압 력을 감소시키며 입각기(stance phase) 마지막 단계인 발가 락 떨어지기(pre-swing)에서 발가락의 미는 힘을 향상시키 는 기능을 가지고 있다. 신발의 크기는 $230 \mathrm{~cm}$ 부터 $275 \mathrm{~cm}$ 까지 착용 시 편안한 크기를 선택하도록 하였고, 일반 신발 은 대상자들이 평상시에 신는 크기를 착용하도록 하였다. 그 러나 굽 높이에 의한 변인을 제거하기 위하여 $3 \mathrm{~cm}$ 이상인 경우는 실험에서 제외하였다. 접촉시간, 보폭길이 및 족저압 은 총 20 분간의 보행 중에 가운데 10 분간 수집된 데이터 의 평균값으로 우측발을 기준으로 하였고, 접촉시간과 족 저압은 발을 전족부(forefoot), 중족부(midfoot) 및 후족부 (hindfoot)로 나누어 분석하였다. 전족부는 중족골이 원위부 에서 끝나는 부위부터 발가락까지의 길이이고, 중족부는 족 근골 원위부부터 중족골 원위부까지의 길이이고, 후족부는 지면접촉부위부터 족근골까지의 길이로 하였다. 정확한 보행
과 신발 착용에 의한 실험을 위하여 대상자의 주관적 느낌을 반영하여 보행 시 현기증, 어지러움, 하지 및 가슴 통증이 있 으면 실험을 중단하였다.

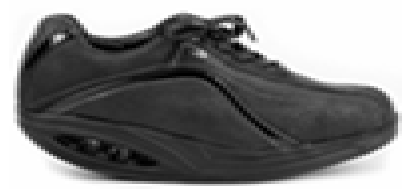

Figure 1. Streamlined shoe

\subsection{Data collection}

모든 측정값들은 윈도우 SPSS 18.0 프로그램을 이용하여 통계 처리하였다. 연구대상자의 연령, 신장 및 체중과 관련 된 일반적 특성은 평균 및 표준편차로 기술적 통계 및 독립 $t$-검정 (independent $t$-test) 을 사용하였고, 두 그룹의 보 행 시 접촉시간, 보폭길이 및 족저압은 독립 $t$-검정으로 검 증하였다. 통계학적 유의성 검증을 위하여 유의수준은 $\alpha$ $=.05$ 로 하였다.

\section{Results}

\subsection{Contact time}

유선형 신발과 일반 신발 그룹 각각 보행 시에 나타난 접 촉시간은 부위별로 Table 2에 제시되어 있다. 전족부, 중족 부 및 후족부 각 부위에서 유선형 신발 그룹이 일반 신발 그룹보다 접촉시간이 모두 통계적으로 유의하게 감소되었다 ( $p<.05)$ (Table 2). 이는 유선형 신발 착용 시에 입각기 시 간의 감소와 상대적으로 유각기 시간의 증가를 의미한다.

Table 2. Contact time on the both groups

$(\mathrm{msec})$

\begin{tabular}{c|c|c|c}
\hline & $\begin{array}{c}\text { Experimental group } \\
\left(\mathrm{n}_{1}=30\right)\end{array}$ & $\begin{array}{c}\text { Control group } \\
\left(\mathrm{n}_{2}=30\right)\end{array}$ & $p$ \\
\hline Forefoot & $62.76 \pm 5.62$ & $72.90 \pm 4.34$ & .000 \\
\hline Midfoot & $56.86 \pm 6.92$ & $61.96 \pm 6.09$ & .000 \\
\hline Hindfoot & $32.66 \pm 5.70$ & $44.86 \pm 5.83$ & .004 \\
\hline
\end{tabular}




\subsection{Step length}

유선형 신발과 일반 신발 그룹 각각 보행 시에 나타난 보 폭길이는 Table 3 에 제시되어 있다. 유선형 신발이 일반 신 발보다 더 큰 보폭길이를 보였다 $(p<.05)$ (Table 3$)$.

Table 3. Step Length on the both groups

(cm)

\begin{tabular}{c|c|c|c}
\hline & $\begin{array}{c}\text { Experimental group } \\
\left(\mathrm{n}_{1}=30\right)\end{array}$ & $\begin{array}{c}\text { Control group } \\
\left(\mathrm{n}_{2}=30\right)\end{array}$ & $p$ \\
\hline Step length & $74.76 \pm 9.49$ & $65.93 \pm 4.57$ & .000 \\
\hline
\end{tabular}

\subsection{Foot plantar pressure}

유선형 신발과 일반 신발 그룹 각각 보행 시에 나타난 족 저압은 부위별로 Table 4 에 제시되어 있다. 전족부의 족저 압은 유선형 신발 그룹과 일반 신발 그룹 사이에 유의한 차 이가 나타나지 않았다 $(p>.05)$. 그리고 중족부와 후족부는 유선형 신발 그룹이 일반 신발 그룹보다 족저압이 통계적으 로 유의하게 증가되었다 $(p<.05)$ (Table 4). 이는 유선형 신 발 착용 시에 후족부 족저압의 감소와 중족부 족저압의 증가 를 의미한다.

Table 4. Foot plantar pressure on the both groups

\begin{tabular}{|c|c|c|c|}
\hline & & & $\left.\mathrm{N} / \mathrm{cm}^{2}\right)$ \\
\hline & $\begin{array}{c}\text { Experimental group } \\
\qquad\left(\mathrm{n}_{1}=30\right)\end{array}$ & $\begin{array}{c}\text { Control group } \\
\left(\mathrm{n}_{2}=30\right)\end{array}$ & $p$ \\
\hline Forefoot & $16.96 \pm 2.63$ & $16.06 \pm 2.87$ & .211 \\
\hline Midfoot & $15.13 \pm 1.71$ & $12.50 \pm 2.38$ & .000 \\
\hline Hindfoot & $11.86 \pm 2.76$ & $13.93 \pm 3.72$ & .018 \\
\hline
\end{tabular}

\section{Discussion}

유선형 신발의 효과를 알아보기 위하여 지금까지의 연구 들은 대부분 정적인 상태에서 하지 근육의 근활성도, 균형 및 보행과 같은 연구들이 시행되어 왔다(Stewart et al., 2007). 유선형 신발의 가장 큰 장점 중 하나는 입각기 (stance phase)에 체중을 감소시킴으로써 보행에 도움을 주는 것이다. 따라서 본 연구에서는 유선형 신발을 착용하고 실제 보행과 유사한 조건을 위하여 트레드밀에서 동적인 보
행을 실시하면서 나타나는 접촉시간, 보폭 및 족저압을 구체 적으로 알아보고자 하였고, 이를 통해 유선형 신발의 긍정적 인 결과를 알게 되었다.

이밖에 보행속도, 접촉면적 및 운동형상학적으로 하지 관 절의 각도를 측정하는 것이 보편적인 측정방법이다. 그러나 본 연구에서는 측정자세를 일치시키고, 보행속도를 3.0 $4.0 \mathrm{~km} / \mathrm{h}$ 범위 내에서 편안하게 걷도록 하고 접촉시간, 보 폭길이 및 족저압을 측정하였다. 접촉시간과 보폭길이는 동 적인 하지 보행능력과 높은 양의 상관성을 보이는 것으로 보고되었으나(Taniguchi et al., 2012), 접촉면적은 측정방법 측면에서 여러 가지 문제점으로 인하여 본 연구에서는 바닥 의 접촉구간을 전족부, 중족부 및 후족부로 구분하여 접촉시 간 및 족저압을 측정하였다.

유선형 신발의 형태는 착용 대상자의 기능부전 및 목적에 따라 기본 바닥 둥근창(basic rocker sole), 발가락 뒤꿈치 둥근창(Heel-to-toe rocker sole), 발가락 쪽 둥근 바닥창 (toe-only rocker), 큰 각도 바닥창 (severe-angle rocker sole), 음성 뒤굽 바닥창(negative heel rocker) 및 이중 둥근 바닥창 (double rocker) 등이 있다(Wunderlich \& Cavanagh, 2001). 발가락 뒤꿈치 둥근창의 형태는 뒤꿈치 와 발가락 쪽의 각도가 큰 형태로 입각기 초기 시 충격 흡수 와 굴림효과를 크게 얻기 위해서 고안되었고, 발가락 쪽 둥 근 바닥창은 발가락 쪽에만 둥근창의 형태를 보이며 발가락 떨어지기 단계(pre-swing)를 용이하게 하고 중간 입각기 (midstance phase)를 연장시킴으로써 엄지발가락의 강직, 망치 발가락, 굳은살, 궤양 및 중족골 궤양 등에 효과적이다. 큰 각도 바닥창은 발가락 쪽에만 둥근 형태를 보이며 발가락 쪽 둥근 바닥창보다 더 큰 각도를 가지기 때문에 발가락 떨 어지기의 용이성을 최대한 향상시키고, 음성 뒤굽 바닥창은 서 있을 때 발 뒤꿈치가 발바닥 볼 높이보다 낮게 위치하여 중족골두의 하중을 크게 제거하여 이 부위의 통증을 완화시 키며 굴림효과를 크게 향상시키게 되며, 이중 둥근 바닥창은 바닥창의 중간 부분이 제거된 완만한 창의 형태로 전후에 2 개의 둥근창을 가지며 발 중앙의 차콧발(Charcot-foot) 변 형 같은 경우에 효과적으로 사용될 수 있다(Taniguchi et al., 2012; Wunderlich \& Cavanagh, 2001). 본 연구에서는 보 편성과 안정성을 고려하여 가장 효과적이고 많이 사용하는 기본 바닥 둥근창 형태의 유선형 신발을 적용하였다.

접촉시간의 결과를 보았을 때, 유선형 신발은 각 구간 별 로 모두 일반 신발보다 유의하게 시간이 감소되었고, 전체적 으로도 감소되었다. 유선형 신발은 신발 바닥창 구조가 둥근 형태로 초기 발 뒤꿈치 닿기(initial contact)부터 발가락 떨 어지기 단계까지 굴림 보행이 이루어져 접촉시간이 짧아지 게 된다(Taniguchi et al., 2012). 일반 신발에 의한 보행은 초기 발 뒤꿈치 닿기 때 하중을 받기 시작하는 반면에 유선 
형 신발에 의한 보행은 하중을 받음과 동시에 중간 입각기 (mid-stance)로 진행되기 때문에 초기 접지 시에 후족부에 가해지는 하중을 감소시키며 접촉시간이 감소하게 되는 것 으로 사료된다(Romkes et al., 2006). 또한 유선형 신발의 후족부 접촉시간의 감소는 초기 접지 시에 발등 배측굴곡 (ankle dorsiflexion)을 일으키는 앞정강근(tibialis anterior) 의 근 피로를 줄여줌으로써 일어난다고 선행연구들에서 보 고되었다(Taniguchi et al., 2012).

보폭길이는 일반 신발 그룹의 $65 \mathrm{~cm}$ 보다 유선형 신발 그 룹에서 $74 \mathrm{~cm}$ 으로 $9 \mathrm{~cm}$ 가 크게 측정되었다. 선행연구를 비 교해보면, Kim과 Chae(2006)는 유선형 신발이 일반 신발 에 비해 보폭길이가 $70 \mathrm{~cm}$ 에서 $75 \mathrm{~cm}$ 으로 $5 \mathrm{~cm}$ 유의하게 증가했다고 하였고, Taniguchi 등(2012)의 연구결과에 따 르면 보폭길이는 보행속도와 양의 상관관계를 보이면서 보 행 에너지 소비에도 긍정적으로 작용한다고 보고하였다. 이 는 유선형 신발을 착용하였을 때, 굴림 보행현상으로 인하 여 운동형상학적으로 지면반발력 증가에 따른 발바닥 굽힘 각도와 하지의 관절운동범위가 증가하면서 보폭길이를 증가 시킨 것으로 고려된다. 이러한 보폭길이 증가는 보행속도에 도 양의 상관성을 갖는 것으로 보고되었다(Romkes et al., 2006).

족저압 연구결과에 의하면, 일반 신발과 비교하여 유선형 신발을 착용하였을 때 후족부의 족저압은 $2 \mathrm{~N} / \mathrm{cm}^{2}$ 감소하 였고, 중족부 족저압은 $3 \mathrm{~N} / \mathrm{cm}^{2}$ 증가하였다. 이는 유선형 신 발 착용이 전족부, 중족부 및 후족부의 족저압을 모두 균등 하게 분산시키는 것을 의미한다. 또한, 전족부 족저압은 통 계적으로 유의하지는 않았지만, 입각기 마지막 단계인 뒤꿉 치 떼기 시 지면반발력을 더 크게 사용한 것을 의미한다. 이 는 Stewart 등(2007)의 유선형 신발을 착용 시 직립자세에 서 일반 신발과 비교하여 전족부의 족저압이 $83 \%$ 가 높게 나타나고 중족부는 $44 \%$ 가 높게 보인다고 보고한 선행연구 결과와도 일치하였다. 이러한 결과는 연구대상자를 측면에서 관찰 시 무게중심이 후방으로 이동되어 있는 자세가 유선형 신발을 착용하면서 전방으로 이동하여 해부학적으로 바른 자세를 유지함으로써 나타난 결과로 사료된다(Mika et al., 2012; Stewart et al., 2007).

본 연구에서의 제한점은 첫째, 대상자 수가 적고 즉각적인 효과만을 비교하였다. 둘째, 실험 전에 실시한 유선형 신발 에 적응시간이 부족하였다. 신발의 적응시간을 더 길게 적용 하였을 때 보다 실질적인 보행측정이 가능해 질 것으로 사료 된다. 셋째, 서로 다른 실험자군으로 인한 보행속도 및 보행 패턴의 부분적 통제로 인하여 구간에 따른 발과 지면의 접촉 시간, 보행 중 족저압의 궤적이 되는 압력중심 속도와 좌우 이동거리 및 보폭길이를 구체적으로 구하지 못하였다. 또한, 동일한 신발을 착용한 조건의 대상자들에게 반복 측정하는
실험 디자인이 함께 고려되어야 할 것이다. 넷째, 대조군에 서 서로 다른 신발 착용으로 인하여 신발의 크기 및 높이의 조건이 다르게 적용되었을 가능성이 있으며, 보행 방향과 발 기준선의 각도인 발축각도, 안정적인 보행을 의미하는 후족 부의 거골(talus)과 종골(calcaneus)이 이루는 거골하 관절 (subtalus joint)의 유연성, 최대 족저압 및 압력중심점의 변 화는 측정하지 못하였다. 다섯째, 고령자 및 내리막 길과 같 은 다양한 보행 환경에서 측정하지 않았기 때문에 본 연구결 과를 유선형 신발이 동적 보행능력의 모든 요소에 미치는 영 향으로 일반화시켜 해석하는 것에는 제한점이 있을 것이다. 따라서 다음 연구는 이러한 제한점들을 보완하여 다양한 측 면에서 유선형 신발의 효과를 측정하는 연구가 계속적으로 이어져야 할 것이다.

\section{Conclusion}

유선형 신발은 정적인 또는 동적인 측면에서 신체의 역학 적 특성을 변화시켜 보행능력에 영향을 미친다. 본 연구를 통하여 유선형 신발을 착용하였을 때 실제 보행과 유사한 동 적인 상태에서 접촉시간, 보폭길이 및 족저압에 긍정적인 영 향을 미치는 것을 알 수 있었다. 이는 보행 시에 유선형 신 발의 구조로 인한 굴림 보행과 안정감 향상으로 접촉시간과 보폭길이가 개선되고, 발에 가해지는 하중을 감소시켜 족저 압이 분산되어 감소된 것으로 보인다. 결과적으로 유선형 신 발 착용은 하지의 역학적 변화를 통하여 보행에 유용한 것으 로 고려되어진다. 이러한 유선형 신발은 산업현장 및 일상생 활에서 보행능력 향상을 위하여 긍정적인 것으로 보이며 이 에 대한 필요성에 대해서 더 많은 연구가 이루어지길 제언하 는 바이다.

\section{Acknowledgements}

These authors thank the subjects who took part in this study. No funding was supported for this work. Conflict of interest: None declared.

\section{References}

Cambron, J.A., Duarte, M., Dexheimer, J. and Solecki, T., Shoe orthotics 
for the treatment of chronic low back pain: a randomized controlled pilot study, J Manipulative Physiol Ther, (4), 254-260, 2011.

Fuller, E., Schroeder, S. and Edwards, J., Reduction of peak pressure on the forefoot with a rigid rocker-bottom postoperative shoe, $J \mathrm{Am}$ Podiatr Med Assoc, 91(10), 501-507, 2001.

Kim, Y.J. and Chae, O.S., The Plantar Pressure Comparison between the Curved Rear Balance Shoes and Normal Shoes, Korean journal of sport biomechanics, 17(3), 173-180, 2007.

Mika, A., Oleksy, L., Mika, P., Marchewka, A. and Clark, B.C., The effect of walking in high- and low-heeled shoes on erector spinae activity and pelvis kinematics during gait, Am J Phys Med Rehabil, 91(5), 425-434, 2012

Moraes, G.F., Mendes, D.P. and Papinni, A.A., Muscular activity in different locomotion plans with the use of various shoes types and barefoot, Work, 41 Suppl 1, 2549-2555, 2012.

Najafi, B., Khan, T., Fleischer, A. and Wrobel, J., The Impact of Footwear and Walking Distance on Gait Stability in Diabetic Patients with Peripheral Neuropathy, J Am Podiatr Med Assoc, 103(3), 165-173, 2013.

Paton, J.S., Thomason, K., Trimble, K., Metcalfe, J.E. and Marsden, J., Effect of a forefoot off-loading postoperative shoe on muscle activity, posture, and static balance, J Am Podiatr Med Assoc, 103(1), 36-42, 2013.

Perry, J., Gait Analysis: Normal and Pathological Function. New Jersey, SLACK, 1992

Romkes, J., Rudmann, C. and Brunner, R., Changes in gait and EMG when walking with the Masai Barefoot Technique, Clin Biomech, 21(1), 75 $-81,2006$.

Stewart, L., Gibson, J.N. and Thomson, C.E., In-shoe pressure distribution in "unstable" (MBT) shoes and flat-bottomed training shoes: a comparative study, Gait Posture, 25(4), 648-651, 2007.

Taniguchi, M., Tateuchi, H., Takeoka, T. and Ichihashi, N., Kinematic and kinetic characteristics of Masai Barefoot Technology footwear, Gait Posture, 35(4), 567-572, 2012.

Waters, R.L. and Mulroy, S., The energy expenditure of normal and pathologic gait, Gait Posture, 9(3), 207-231, 1999.

Wunderlich, R.E. and Cavanagh, P.R., Gender differences in adult foot shape: implications for shoe design, Med Sci Sports Exerc, Apr 33(4), 605-611, 2001

\section{Author listings}

Jae-Hun Shim: clinicalpt@bu.ac.kr

Highest degree: Ph.D, Department of Health Science, Hanyang University

Position title: Assistant Professor, Department of Physical Therapy, Baekseok University

Areas of interest: Industrial medicine

Hwa-Soo Koong: goong@konyang.ac.kr

Highest degree: $\mathrm{PhD}$, Department of Dental Medicine, Kyunghee University

Position title: Associate Professor, Department of Dental Hygiene, Konyang University

Areas of interest: Clinical Anatomy, Industrial medicine

Seung-Chul Chon: keyjune@konyang.ac.kr

Highest degree: $\mathrm{PhD}$, Department of Physical Therapy, Yonsei University Position title: Assistant Professor, Department of Physical Therapy, Konyang University

Areas of interest: Human engineering, Musculoskeletal disorders

Date Received : 2013-09-27

Date Revised :2013-10-21

Date Accepted : 2013-11-20 